\title{
Government and Physical Education
}

David Kirk, University of Strathclyde and University of Queensland

\section{Introduction}

Government is involved in physical education primarily in two ways, through legislating for national curricula for schools and through the development of sport policy. Behind this relatively simple statement, however, lies a tangled web of complexity. Complexity is an enduring feature of the governance and organisation of sport in the UK generally, and of physical education's relationship to sport more specifically (Green, 2008). Within such complexity, debates are bound to take place.

In this chapter, we will explore some of the lines of debate that constitute the tangled web of the relationship of government and physical education. One line of debate centres on what we mean by 'government' and 'physical education'. As we reflect on this issue and the questions it raises, other lines of debate emerge. Some of these criss-crossing lines are: the 'relative autonomy' of educational systems, the operation of power and vested interests, participation versus elite sport, neoliberal practices in education and sport, the role of academic research in policy development, and the obdurate challenge of educational change. In order to follow these lines of debate, we can draw on insights offered by fields such as sport policy, educational policy sociology, and curriculum studies.

The chapter follows these debates and the cross-cutting and inter-related insights to them offered by these fields of study. After a brief definition of the core notions of 'government' and 'physical education', the chapter considers in turn the two main points of connection, national curricula and sport policy. For the sake of coherence in the chapter, the examples 
and evidence are from the UK, with a particular focus on developments in England. Readers who do not have experience of the UK are invited to consider the extent to which events in other countries do or do not follow the patterns outlined here.

\section{'Government' and 'school physical education'}

Before we can begin to examine their relationship, we need a view on what we mean by the terms 'government' and 'physical education'. The most recent policy for sport in the UK, Sporting Future (HM Government, 2015) is clear about what 'government' means. The writers outlined three levels of 'government' for sport policy: central, local and devolved.

Central government is the Her Majesty's Government, based in Westminster, with a UK-wide remit. Central government's role, according to Sporting Future, "is to set the high level policy that guides how public money is invested rather than to make each and every funding decision". According to the authors of Sporting Future, Government operates on an 'armslength principle' across a number of its departments. As such, "Government will not generally prescribe which organisations, sports or types of activity should be funded; that is the role of UK Sport, Sport England, Public Health England (PHE) and others" (HM Government, 2015, p.12). Local government refers primarily to Local Authorities, "the biggest public sector investors in sport and physical activity” (HM Government, 2015, p.13), who also have an important role to play in bringing together the work of a range of other agencies such as NBGs of sport, schools, clubs, health and the private sector. Devolved government refers to responsibilities for elite sport and education in Scotland, Wales and Northern Ireland. In this chapter, each of these levels will be referred to as Government, the formal legal entity for governing in the UK. 
The meaning of 'physical education' has had a long and disputatious history (Kirk, 1992). Here we will use the term to refer specifically to those activities undertaken during school curriculum time and in extra-curricular time, where formally sponsored by the school and where a majority of pupils are routinely included. The School Games aims to be inclusive of as many children and young people as possible, at least in principle, and arguably could be considered to be part of or an extension of school physical education (https://www.yourschoolgames.com/how-it-works/what-school-games/). The many sportspecific competitions at local, county and national levels we will not count as school physical education since they routinely exclude a majority of pupils. Neither will we include in this definition the many community, club-based sport and physical activity opportunities available to young people on a voluntary basis, though these activities will be considered in the second part of the chapter.

We can see already that complexities, qualifications and nuances emerge around notions of 'government' and 'physical education'. Armed with these definitions, we can now turn to the two primary ways in which government at each of the three levels identified relates to school physical education. The first of these is national curricula.

\section{National curricula}

Debates around national curricula reveal the extent to which the nature of school physical education, its form and content, has been called into question by various individuals and groups, and the range of parties who have vested interests in the character and conduct of physical education. These debates also show the limited influence Government has over the form and content of school physical education, despite the existence of the National Curriculum Physical Education (NCPE). 
There are national curricula operating on each of the 'home nations' that comprise the UK. The earliest is the NCPE in England and this is the focus of the discussion here. Some though not all of the issues that are debated in relation to the NCPE apply to other countries' national curricula for physical education. The national curriculum sets out programmes of study that all state funded schools are required to follow by law, though Academy Schools and private schools are exempt (Roberts, 2018). While attainment targets are outlined for each subject, and they are subject to Ofsted inspections, schools have considerable freedom to determine how these might be reached.

This is the current situation. The passing of the Education Reform Act 1988 by the Thatcher Conservative government created the necessary legislation for a national curriculum. As the House of Commons Briefing paper by Roberts (2018) reveals, the national curriculum has been revised regularly since its implementation in the late 1980s.

For physical education, free from the dictates of high school examinations for most of its history, this was the first action by Government to specify the nature of school physical education since the publication of a series of Syllabuses between 1909 and 1933. As I noted close to the time, the NCPE marked "a watershed in British physical education discourse, a new moment in the production of definitions for physical education" (Kirk, 1992, p.2). This was in part because it was borne out of controversy and strenuous debate. Engineered by the right wing of British politics in the lead up to the 1987 General Election which brought Margaret Thatcher to power for a third time, a debate about school physical education erupted in the mainstream and professional press. The debate was over the place of team games and sports in physical education, fuelled by an allegation that physical education was 
being subverted by 'trendy left wing radicals' who wanted to rid the subject of sport and competition. The titles of articles appearing in newspapers of the time capture the flavour of the debate: 'Worried Sports Chiefs Call for Games Policy' (December 1985); 'Pupils' Views of Sport Spark Competitive Games Row' (January 1986); 'Get In There And Win' (July 1986); 'Howell (former Sports Minister) Calls for Sports Re-think' (August 1986); and 'Passing the Fitness Test?' (March 1987).

This final article, which appeared in The Listener, was the basis of the script for an episode of the BBC's current affairs programme Panorama, which aired in March 1987 and was titled 'Is Your Child Fit for Life'. In it, the journalist Richard Lindley built on the debate in the print media to create an impression that Britain's proud tradition of team games and sport was indeed in jeopardy in state secondary schools, targeting for criticism in particular the English Sports Council's slogan of 'Sport for All'. Lindley's reporting conveys to viewers that teachers' efforts at inclusion were undermining 'standards' and denying the 'realities of life', such as success and failure through competition. More than this, left wing inspired physical education teachers were subverting Britain's success as a sporting and trading nation and, indeed, as an international power (see Kirk, 1992, Chapter 1).

An Editorial in the Times Educational Supplement provides a typical example of the material Lindley had to work with. In a July 1986 issue of the TES, the Editor wrote:

What is to be made of the 1960-ish ideology which prompts ageing PE organizers to decry traditional forms of sporting competition on the basis of value-judgement that are wildly at odds with those of the society the schools exist to serve? Last weekend, London TV viewers were treated to a comprehensive school where pupils engaged in 
stool-ball, a primitive forerunner to cricket played with a softball bat which, The Times man said, 'allows both sexes to play and is not competitive'. Viewers must have reflected that one thing is fairly certain; the West Indian pace attack was not reared on stool-ball and stool-ball is not going to help England find a quick bowler. (Editor, TES, July 1986)

Physical educators attempted to answer back. Colin Hardy (1986) of Loughborough University pointed out in the British Journal of Physical Education's newsletter that far from declining, evidence from surveys showed that participation in some team games was actually increasing. Terry Williamson, Editor of The Bulletin of Physical Education, wrote of his concern that a self-interested lobby group was gaining such a high profile just prior to a General Election and the promise of a national curriculum if the Tories won. The Physical Education Association (the forerunner to the Association for Physical Education [afPe]) went to the length of creating a special Commission to investigate whether sport was declining in school physical education, which reported in March 1987. Although the Commission began with wider intentions, the PEA inquiry could not avoid being shaped by the issue of whether and to what extent school physical education had a primary responsibility to produce elite performers for Britain's international sports teams (Kirk, 1992, pp. 6-7).

Despite these protestations, the impression was sown into public opinion that school physical education was in danger of being overtaken by dangerous anti-tradition radicals. John Evans (1990) insightfully argued at the time this was because the protagonists for the Right had tapped a tender nerve in the psyche of the population centred on the powerful symbolism of sport as a cherished aspect of British cultural heritage and Britain's status as an international power. 
The NCPE was created in the immediate aftermath of this debate. Penney and Evans (1999) document in detail subsequent developments, which resulted in an essentially sport-based version of physical education. This is not to say the NCPE took this form without some struggle and resistance from physical educators and other stakeholders. As Penny and Evans recall, the Working Group convened and tasked with providing recommendations to the Secretary of State for Education produced an interim report which sought to balance the wide range of practical physical activities. This report was rejected, however, for not giving enough emphasis to sport, and the Working Group had to amend their recommendations to accommodate this request from Government.

We might conclude on the basis of this narrative of the origins of the NCPE that school physical education was at this time vulnerable to powerful vested interests, particularly those who support the right wing of British politics. It was certainly no accident that a media storm engulfed school physical education in the lead up to a high stakes General Election in which a controversial Prime Minister who had championed a form of neoliberal politics was standing for the third time. Evans was right in his assessment that physical education's associations with games and sports, cherished traditions within Britain's cultural heritage, made it a plausible 'fall guy' for other ills in British society at the time.

At the same time we might ask, does this example suggest that Government and some vested interests can determine what form school subjects such as physical education might take? Theories of the 'relative autonomy' of education systems from Government control were much discussed by Leftist scholars of education in the 1970s and 1980s (eg. Hargreaves, 1982; Whitty, 1985). The question was, Can Education Change Society? (Apple, 2013). 
Apple's answer is yes, it can, but not necessarily in the ways Left scholars would wish for, in terms for example of greater social justice and equity. Consistent with Apple's analysis (2013), the birth of the NCPE shows how the political Right have been adept at manipulating popular sentiment for their own interests, utilizing the media and recruiting others to their cause, often unwitting, as in the case of various NGBs of sport in the mid 1980s who had no ostensible political affiliations. If the creation of a national curriculum in England in the late 1980s marked a new moment in Government's attempts to exert overt control of the school curriculum, we might conclude along with Basil Bernstein (2000) that education's relative autonomy from the state was being continuously eroded and reduced over time. We will see when we turn to the example of sport policy how that process has played out in another context, beyond the education system itself. But when we consider what happened next, once a sport-based form of the NCPE had been legislated into existence, we identify some further points of complexity and debate concerning the relationship between Government and school physical education.

Because, ironically, the form of physical education that constructed and constituted the NCPE did not look very much different from what had existed previously, from the 1960s up to 1988. Extensive research by Kane (1974), Whitehead and Hendry (1976) and Underwood (1983) showed that there was much local variation among schools across England in terms of the specific games and sports offered, the time allocated to types of activities, and so on. But the main themes that organised physical education from the 1960s remained intact post-1988. These themes, now consolidated in the NCPE as official Government policy, were that physical education was an emphatically practical subject, that it typically covered a wide range of physical activities including games and sports, gymnastics, swimming, dance, health-related fitness, athletics and outdoor activities, and that in principle there should be 
breadth and balance of these activities across school programmes. Penney and Evans (1999) noted a message that emerged from the process of constructing the NCPE, that it 'was clearly something to be delivered but not defined by teachers' (p.38).

Although as we noted earlier the NCPE had been revised several times since its inception, most recently in 2014, it has received nothing like the media exposure and overt Government intervention as it did in the mid-1980s. Arguably, the development of Specialist Sports Colleges, School Sports Partnerships and the involvement of the Youth Sport Trust (something to which we return shortly) had a significant impact on the context in which physical education teachers worked (Jung, 2014; Ives, 2014; Phillpots, 2013). But, for all its energy and innovation, the YST was never able to influence the NCPE itself.

Consequently, it might be argued that the current form of the NCPE differs little in substance from the original. Moreover, as the education policy sociology approach favoured by Penney and Evans (1999) shows, since there is always a degree of policy slippage in any process like the NCPE, practice on the ground often contrasts with the education policy aspirations. Within curriculum studies, a similar concept of 'policy mutation' (Priestley, 2010) describes how ideas undergo changes as they are implemented in practice in different places over time.

The NCPE like many other educational policies is no stranger to the obdurate challenge of educational change, and has been affected by policy slippage and mutation. As such, researchers have pointed to a range of unintended consequences of the NCPE. For example, Williams and Bedward (2001, p. 53) argued the 1992 and 1995 NCPE orders confirmed the centrality of competitive sport which "privileged a curriculum that has much greater relevance to boys than to girls", a point confirmed by Smith et al.'s (2007) empirical research 
with 15 and 16 year olds in the north of England. Zwozdiak-Myers' (2004) study in the East of England showed that games dominated the curricular and extracurricular experiences of upper primary school pupils, with no outdoor education in year 6 and no dance or swimming in year 7, thereby undermining the principle of breadth and balance. More recently, Griggs (2016) reported that another Government initiative, the Primary PE and Sports Premium, which has provided funds to schools to build the legacy of the 2012 London Olympic Games, has now consolidated competitive sport in primary schools, most often organised by boughtin sports coaches. In this example we can see how, through targeted funding, Government has been able to open up a space for the operation of neoliberal practices, in this case centred on outsourcing (Williamson et al., 2011). Another study of primary schools by Ward and Quennerstedt (2016) shows that the multi-activity form of physical education embedded in the NCPE was a 'smorgasbord of looks-like-sport'. This curriculum consists of activities that appear different but 'taste the same' in the sense that they are part of a configuration of the practice of physical education-as-sports-techniques that the NCPE enables (Kirk, 2010).

Government may seek to have influence over the nature of school physical education through the NCPE and other Government-sponsored activities that support it, such as Ofsted inspection, forms of teacher education and specific and time-limited initiatives like the Primary PE and Sport Premium. And at one level, this influence could be viewed as significant. But this influence is not, on the evidence and argument presented here, completely determined by Government, and there is the capacity in the educational system for a 'relative autonomy'. There is at least one other primary form of relationship between Government and school physical education, through sport policy, which offers a contrast and further complexity to the national curricula example. 


\section{Sport Policy}

Debates in sport policy reveal that 'physical education' and 'sport' communities operate in separate spheres. While school physical education is often implicated in sport policies, it is rarely discussed explicitly. This is surprising at one level since, as we have just noted, physical education is, for all intents and purposes, 'sport-based' or, as I have argued elsewhere, 'sport technique-based' (Kirk, 2010). It is also surprising on another level since, even though large sums of public money fund school physical education programmes, specialised equipment and facilities, teachers' salaries and their training programmes in schools and universities, this considerable investment by Government is, as we will see, rarely considered in sport policy.

As already noted, the most recent sport policy to be produced by Government is Sporting Future subtitled $A$ new strategy for an active nation (HM Government, 2015). It is the latest of a whole series of Government sport policies since the 1990s, which includes Playing to win: A new era for sport, (DCMS, 2008), Game Plan (DCMS/ Strategy Office, 2002), A Sporting Future for All (DCMS, 2002), and Sport, Raising the Game (DNH, 1995). The first and the most recent are Conservative or Coalition Government documents, while the other three were produced under New Labour. Despite these differences in politics, the policies are underpinned by similar values and pursue similar outcomes, though often with somewhat different means.

The production of these policies stands in stark contrast to a reticence on the part of Government to become involved in the governance and funding of sport prior to the $1960 \mathrm{~s}$. This said, signs of ruling class interest in connecting sport with national identity can be found 
as early as the 1920s through the work of the National Playing Fields Association and later the Central Council for Physical Recreation (CCPR) (Hargreaves, 1986; Kirk, 1992). The report of the Wolfenden Committee Sport and the Community (CCPR, 1960) is generally acknowledged as a key moment in which Government began to be drawn into a more explicit relationship to sport. The Wolfenden Committee had a wide remit to investigate and report on all aspects of British sport, including coaching, facilities and the media. In the course of its report, the Committee expressed its deep conviction that participation in sports and games was an inherently virtuous activity and that sportsmanship and fair play had a significance in British society of the time that went well beyond the playing field. In expressing this view, they borrowed heavily from the games ethic of the major English Public Schools, but expressed here as a value held by most if not all of British society rather than the minority who attended these schools (Kirk, 1992). The upshot of the Wolfenden Report, supported by many other sports lobbyists, was the establishment in 1965 of the Sports Council of Great Britain, setting the future course of increasing and direct Government involvement in sport. Given its emphasis on sport as a virtuous activity, Sport in the Community was also the quintessential statement of 'traditional physical education' antagonists in the 1980s debate were able to draw upon so effectively to support competitive team games at the core of the NCPE (Kirk, 1992).

Between the appearance of the first Government sport policy in 1995 and the most recent 20 years later, concepts of 'government' in the UK have undergone considerable change. Phillpots (2013) argues from the disciplinary perspective of public policy analysis that sports policy-making does not fit the pattern of Government involvement that has evolved in its relationships with some other public spheres, which involves the dispersal of power to networks and partnerships and an array of 'para-statal' bodies. Policy analysts sometimes 
refer to this approach as 'New Governance'. She suggests that while sport as a field of practice gives the appearance of 'New Governance', sport policy-making is in fact increasingly 'centrally managed, monitored and controlled' through mechanisms like Public Service Agreements (PASs) and Key Performance Indicators (KPIs). The extent to which sport has its own particular pattern of Government involvement is in itself a matter for debate. Indeed, there may be important parallels with education as a field, a point we will come to shortly.

Our interest here, though, is more narrowly focused on how school physical education is positioned within this series of Government produced sport policies. Given what we learned from the 1980s debate, we might expect a more or less explicit alignment between school physical education and the production of elite sports performers. While this relationship forms an undertone in each of these policies, it is rarely made explicit. Certainly, it is hard to find credit being given to physical education teachers in any of these documents when international sports performers are successful, a good case in point being the London 2012 Olympics.

At the same time, and as an effect of these policies in themselves, sport has shifted rapidly from the situation in the $1980 \mathrm{~s}$, where it was dominated by amateurs, to the situation now, where most elite level sport is professional. Another important change during this 20 years period, and arguably another effect of these policies, has been the massive growth in community-based sport for children as young as four and five years of age (Kirk, 2005). Sport has also developed as a business. Indeed, one of the UK's marketable products is the provision of high quality venues for elite sport events such as Olympic Games, European and World Championships, and specialised historic events such as the Open Golf Championship 
and Wimbledon. As such, sport has become increasingly a source of employment and careers for growing numbers of people in the UK, as well as a site for volunteering.

Sporting Future spans this whole gamut of issues, from participation to performance sport, early years to adults, amateur to professional, volunteering to employment, infrastructure and facilities, leadership and training, and more besides. Significantly and surprisingly, it has very little to say about school physical education. Where physical education is mentioned, it is by the abbreviation PE, and only in relation to disabled children and the Primary PE and Sport Premium (pp. 34-5). Even though Government at Local Authority level spends many millions of pounds per year to fund school physical education through the provision of teachers' salaries, teacher education courses, and specialised facilities and equipment in schools, this is the sole mention in the entire 80 page document. This is not to say children and young people are neglected, because there are many pages of policy that refer directly to them. Even when Sporting Future is discussing children and young people's sport and physical activity in a school context, there is no mention of physical education. This is a remarkable and somewhat puzzling state of affairs. At the very least, school physical education is marginalised in this document; it certainly cannot be said to be held in high esteem by the writers.

In contrast, in New Labour's 2008 document Playing to Win, the centrepiece of the approach to sport for young people was the Physical Education and Sport Strategy for Young People (PESSYP). This strategy replaced the Physical Education, School Sport and Club Links (PESSCL) strategy, which was in place between 2003 and 2008. PESSCL itself was an attempt to bring together and provide some degree of 'joined-up' coherence to up to eight separate initiatives. According to the authors of Playing to win, Government investment in physical education and school sport, centred on these two strategies, amounted to $£ 2.2$ billion 
between 2003 and 2011. In order to 'deliver' the main outcomes of the PESSYP, the authors of Playing to win proposed that the Youth Sport Trust coordinate a network of School Sport Partnerships centred on Specialist Sports Colleges. Meanwhile, Sport England was to work with the Youth Sport Trust to strengthen links between schools and community-based sports clubs and develop provision for young people up to age 19 outside of school hours. Building on what the authors claimed was a "solid platform" created by the PESSCL strategy, this coordinating work carried out in collaboration between these two key players was intended to produce more coaches for schools and colleges (though we might note, not teachers). Playing to Win set out an infrastructure for this work centred on PESSYP. There was already in place a national network of over 200 Competition Managers to encourage inter-school sport. This collaboration was intended to produce a national scheme of sporting league tables for schools, a network of multi-sports clubs with provision for disabled young people, a national programme of intra-school sport, and the use of sporting celebrities as 'sport ambassadors', to motivate young people to take part in competitive sport.

In the event, New Labour fell from power in 2010 and the plans set out in Playing to Win were seriously undermined. While this policy document appears to give much more credence to school physical education, careful analysis reveals that very little is said about the NCPE, the core statutory requirement in schools. Instead, the Youth Sport Trust created a strategy that was concerned with the amount of physical education pupils received, but said little about the nature of physical education itself. Various sources of evidence of the effects of PESCCL were available to the writers of Playing to Win, including annual monitoring of amounts of physical education by consultancy firm TNS- BMRB, detailed case study work by the 'Loughborough Partnership', and a major three years study by Ofsted (Kirk, 2009). This evidence was generally positive about the benefits of the PESCCL strategy. But other 
research by academics, such as Smith et al. (2007), Kay and Bradbury (2009) and Flintoff (2008) suggested that the massive investment of public money centre on PESSCL had had little if any impact on traditional practices in school physical education. Indeed, Flintoff (2008) argued that teachers who wanted to seemed powerless to bring about transformative changes within this environment. While the School Sport Partnership she studied was providing more opportunities to be more physically active than had previously been available for a number of young people, including girls and young women, she suggested that a competitive sport discourse continued to dominate physical education and school sport, despite teachers' best efforts.

For all that Playing to Win sought to put in place a more connected, 'joined-up' system of physical education and sport for young people, an aspiration echoed in Sporting Future, school physical education seems to have remained in many respects untouched by Government sport policy developments. Since it receives barely a mention in Sporting Future, it would appear unlikely that this Government policy will impact on school physical education except, perhaps, to uncouple whatever aspects of its work had already been joined to other parts of the system of sport and physical activity for young people. There is no mention either of the Association for Physical Education which represents teachers across the UK, and only passing mention of the Youth Sport Trust.

On the other hand, Sporting Future appears to have promoted Sport England to a central role in Government strategizing, where this organization takes over many of the roles previously awarded to the Youth Sport Trust as a Non-Government Organization. In this we might find further evidence of Philpotts' claim that the field of sport policy evidences a different pattern of Government involvement than other public spheres, with only the appearance of 
partnership and networking. Sporting Future may indeed have done away with any pretense of 'New Governance'. Or, as Stephen Ball (2017) argues from the position of educational policy sociology, what we are witnessing in educational policy (and we can analogize in sport policy too) is not an equal or rationale re-distribution of power from Central Government to a range of other para-statal agencies. Instead, he suggests that we are seeing in the apparently contradictory trends of concentration and dispersal of power a 'new modality of state power, agency and action' (Ball, 2017, p. 221).

\section{Conclusion}

This analysis suggests that there is no straightforward way to characterise the relationship between Government and school physical education, and that indeed this relationship consists of a tangled web of complex issues. As far as Government is concerned, physical educators seem to have had limited capability over at least a 30 years period between the mid 1980 s until 2015 to be heard and taken seriously. Early in the emergence of the Youth Sport Trust, many physical educators were excited by the possibility that a leader capable of having an influence on Government had arrived in the form of Sue Campbell. It is a debate in itself whether school physical education benefitted from the Youth Sport Trust's decade or so in the sun (see Jung, 2014). In the mid 1980s, physical education was used by forces on the Right of politics to advance their own interests by talking up the importance of competitive team games. Physical education has lived with this legacy ever since which, arguably, may have rendered transformative change all the more difficult.

At the same time, school physical education continues to feature in the NCPE by law, and Government continues to spend many millions of pounds to support this legal requirement. In Sporting Future, Government does appear to be very interested in children's and young 
people's lifelong participation in physical activity. Its does not, however, appear to see school physical education as it is currently configured, with specialist and expensively trained teachers, as part of that task. We might speculate whether physical education's absent presence in Sporting Future hints at some new means of providing for this aspiration for lifelong participation, perhaps through a neoliberal mechanism such as exogenous privatization (or outsourcing) to other providers than physical educators. Shirl Hoffman prophesised just such a scenario for physical education in the US as long ago as 1987, which some would argue has indeed happened there (see Kirk, 2010), and is already happening in primary schools in England (Griggs, 2016).

It is a further curiosity that much of the development in the fields of education and sport that directly and indirectly impact on school physical education appear to be uninformed by the burgeoning volume of scholarly research produced in the past 30 years. Physical educators seem neither capable nor interested in using this valuable resource to join collectively in representing their own and their field's best interests. Neither do researchers seem capable of communicating this valuable information to teachers and policy-makers. One of the most urgent debates that might be undertaken by physical educators in schools in all parts of the UK is whether school physical education has a future and, if it does, what would we ideally wish it to look like.

\section{Summary}

Government and physical education have a complex and many-sided relationship. The two main avenues that exist for this relationship in the UK are national curricula and sport policy. National curricula operate through the power of law, while sport policy identifies priorities and targets for funding and development. A debate about competitive team games in physical 
education shaped in the mid-1980s shaped the NCPE, and influence that has lasted to the present day. In contrast, physical education is largely omitted from mention in the most

recent sport policy document, Sporting Future. Despite the apparent desire from both sides of politics for 'joined-up' policies and practices, these examples of the NCPE and sport policy development show that their aspiration has yet to be achieved.

\section{Questions for reflection}

1. Should Government have a more direct influence over the nature of school physical education, or should teachers and pupils have a bigger say?

2. Is the amount of public money Government spends on school physical education justified?

3. Should school physical education be more closely linked to the development of elite sports performers?

4. What might be the most appropriate place for school physical education in sport policy?

5. What should school physical education look like in the future?

\section{Further reading/resources}

Green, K. (2008) Understanding Physical Education. London: Sage.

This book provides a comprehensive overview and introduction to physical education's education and sport relationships. It is one of the few texts that spans both field of literature and so provides a useful introduction of key concepts from a number of disciplines.

Her Majesty's Government (2015) Sporting Future: A new strategy for an active nation. London: Author. 
This is the most recent national sport policy strategy. It provides a useful insight into Government priorities for funding and development. The policy itself is comprehensive and offers a good view of how Government sees the field of sport.

Penney, D. and Evans, J. (1999) Politics, Policy and Practice in Physical Education, London: Routledge.

This is the definitive text in physical education to draw on an educational policy sociology perspective. Although the focus is the NCPE in England up until the mid-1990s, the analysis retains its currency in the present day.

Phillpots, L. (2013) An analysis of the policy process for physical education and school sport: The rise and demise of school sport partnerships, International Journal of Sport Policy and Politics, 5 (2), 193-211.

This paper provides a good introduction to the use of concepts from public policy analysis applied to physical education. It also presents a very good analysis of developments during the New Labour era and of the key players active in policy development and implementation in the first decade of the 2000s.

\section{References}

Apple, MW. (2013) Can Education Change Society? New York: Routledge.

Ball, SJ. (2017) The Education Debate, Bristol: Policy Press ( $3^{\text {rd }}$ Edition). 
Bernstein, B. (2000) Pedagogy, Symbolic Control and Identity: theory, research, critique, London: Rowman and Littlefield Publishers.

Central Council for Physical Recreation (1960) Sport in the Community ('The Wolfenden Report'), London: Author.

Department of Culture, Media and Sport (2008) Playing To Win: A New Era for Sport London: Author.

Department of Culture, Media and Sport (2002) A Sporting Future for All London: Author.

Department of Culture, Media and Sport / Strategy Office (2002) Game Plan: A strategy for delivering government's sport and physical activity objectives London: Cabinet Office.

Department of National Heritage (1995) Sport, Raising the Game London: HMSO.

Evans, J. (1990) Defining the subject: The rise and rise of the new PE? British Journal of Sociology of Education, 11(2), 155-169.

Flintoff, A. (2008) Targeting Mr Average: participation, gender equity, and school sport partnerships, Sport, Education and Society, 13(4), 393-411.

Green, K. (2008) Understanding Physical Education. London: Sage. 
Griggs, G. (2016) Spending the Primary Physical Education and Sport Premium: a West Midlands case study, Education 3-13, 44:5, 547-555.

Hardy, C. (1986) Competitive team sport and schools, British Journal of Physical Education, 17(2), ix-X.

Hargreaves, A. (1982) Resistance and relative autonomy theories, Problems of distortion and incoherence in recent Marxist analyses of education. British Journal of Sociology of Education, 3(2), 107-126.

Hargreaves, J. (1986) Sport, Power and Culture, Cambridge: Polity.

Her Majesty's Government (2015) Sporting Future: A new strategy for an active nation. London: Author.

Ives, H. (2014) The Social Construction of Physical Education and School Sport: Transmission, Transformation and Realization. Unpublished PhD Thesis, University of Bedfordshire.

Jung, H. (2014) The Social Construction of Pedagogic Discourse in Policy for Physical Education and School Sport. Unpublished PhD Thesis, University of Bedfordshire.

Kane, JE. (1974) Physical Education in Secondary Schools: Schools Council Inquiry, London: Macmillan. 
Kay, T. and Bradbury, S. (2009) Youth sport volunteering: developing social capital? Sport, Education and Society, 14(1), 121-140.

Kirk, D. (2010) Physical Education Futures, London: Routledge.

Kirk, D. (2009) Recent policy developments in physical education and youth sport in the England: A critical perspective. Paper prepared for the International Conference on Promoting and Developing Sport for Youth: Further Cooperation and Collaboration in School and Community, The Ministry of Education, Culture Sport, Science and Technology (MEXT), Tokyo, December.

Kirk, D. (2005) Physical education, youth sport and lifelong participation: The importance of early learning experiences, European Physical Education Review, 11(3), 239-255.

Kirk, D. (1992) Defining Physical Education: The social construction of a school subject in postwar Britain. London: Falmer.

Penney, D. and Evans, J. (1999) Politics, Policy and Practice in Physical Education, London: Routledge.

Phillpots, L. (2013) An analysis of the policy process for physical education and school sport: The rise and demise of school sport partnerships, International Journal of Sport Policy and Politics, 5 (2), 193-211. 
Priestley, M. (2010). Curriculum for Excellence: transformational change or business as usual? Scottish Educational Review, 42(1), 23-36.

Roberts, N. (2018) The School Curriculum in England: Briefing Paper Number 06798. London: House of Commons Library.

Smith, A., Thurston, M., Lamb, K. and Green, K. (2007) Young people's participation in National Curriculum Physical Education: A study of 15-16 year olds in North-West England and North-East Wales, European Physical Education Review, 13: 165-194.

Underwood, G.L. (1983) The Physical Education Curriculum in the Secondary School: planning and implementation, Lewes: Falmer.

Ward, G. and Quennerstedt, M. (2016) Transactions in primary physical education in the UK: a smorgasbord of looks-like-sport, Physical Education and Sport Pedagogy, 21(2), 137-152.

Whitehead, N. and Hendry, L.B. (1976) Teaching Physical Education in England, London: Lepus.

Whitty, G. (1985) Sociology and School Knowledge: Curriculum theory, research and politics, London: Methuen.

Williams, A. and Bedward, J. (2001) Gender, culture and the generation gap: Student and teacher perceptions of aspects of National Curriculum Physical Education, Sport, Education and Society, 6: 53-66. 
Williams, BJ., Hay, PJ. and Macdonald, D. (2011) The outsourcing of health, sport and physical educational work: A state of play, Physical Education \& Sport Pedagogy, 16 (4), pp.399-415.

Williamson, T. (1986) From the Editor. Bulletin of Physical Education, 22(2), 6.

Zwozdiak-Myers, P. (2004) Breadth, balance and relevance: A report of Year 6 and Year 7 pupils' curricular and extra-curricular experiences in the East of England. British Journal of Teaching Physical Education, 35(2), 43-50. 